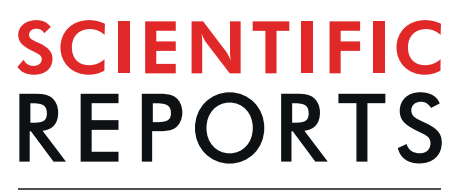

natureresearch

Check for updates

\title{
New LncRNAs in Chronic Hepatitis C progression: from fibrosis to hepatocellular carcinoma
}

\author{
Adriana Camargo Ferrasi ${ }^{1,2} \llbracket$, Geysson Javier Fernandez ${ }^{3}$, Rejane Maria Tommasini Grotto ${ }^{2,4}$, \\ Giovanni Faria Silva ${ }^{1}$, Joao Goncalves ${ }^{5}$, Marina C. Costa ${ }^{6}$, Francisco J. Enguita ${ }^{6}$ \& \\ Maria Inês de Moura Campos Pardini ${ }^{1,2}$
}

Hepatocellular carcinoma (HCC) is the third leading cause of cancer-related death in the world, and about $80 \%$ of the cases are associated with hepatitis B or C. Genetic and epigenetic alterations are accumulated over decades of chronic injury and may affect the functioning of tumor suppressor genes and protooncogenes. Studies have evidenced the role of Long non-coding RNAs (LncRNA) with oncogenic or tumor suppressor activities, suggesting a great potential in the treatment, diagnosis or indicator of prognosis in cancer. In this context, the aim of this study was to evaluate the global expression profile IncRNA in hepatic tissue samples with different stages of fibrosis associated with chronic hepatitis C, HCC and normal liver, in order to identify new IncRNAs that could contribute to study the progression of hepatic fibrosis to HCC associated with chronic hepatitis C. RNA-Seq was performed on Illumina NextSeq platform to identify IncRNAs expressed differently in 15 patients with chronic hepatitis $\mathrm{C}$, three patients with $\mathrm{HCC}$ and three normal liver specimens. When the pathological tissues (fibrosis and carcinoma) were compared to normal hepatic tissue, were identified 2, 6 e 34 differentially expressed IncRNAs in moderate fibrosis, advanced fibrosis and HCC, respectively. The carcinoma group had the highest proportion of differentially expressed IncRNA (34) and of these, 29 were exclusive in this type of tissue. A heat map of the deregulated IncRNA revealed different expression patterns along the progression of fibrosis to HCC. The results showed the deregulation of some IncRNA already classified as tumor suppressors in HCC and other cancers, as well as some unpublished IncRNA whose function is unknown. Some of these IncRNAs are dysregulated since the early stages of liver injury in patients with hepatitis C, others overexpressed only in tumor tissue, indicating themselves as candidates of markers of fibrosis progression or tumor, with potential clinical applications in prognosis as well as a therapeutic target. Although there are already studies on IncRNA in hepatocellular carcinoma, this is the first study conducted in samples exclusively of HCV-related liver and HCV HCC.

Hepatocellular carcinoma (HCC) is the sixth most common type of cancer and the third leading cause of cancer-related death in the world ${ }^{1}$. Surgical resection and liver transplantation are the main resources for treatment. However, the results are limited, and the prognosis is poor due to late diagnosis, distant metastases and high risk of postoperative recurrence ${ }^{2-4}$. Due to unspecific or absent symptoms in HCC, early detection requires the bi-annual monitoring of individuals at risk through ultrasound with or without assessment of the alpha-fetoprotein (AFP) biomarker ${ }^{5}$. Environmental and genetic factors are involved in hepatic carcinogenesis. About $80 \%$ of the cases are associated with hepatitis $\mathrm{B}$ or $\mathrm{C}^{6,7}$, mainly due to the development of cirrhosis after years of chronic infection ${ }^{4}$. Despite advances in the diagnosis and treatment of hepatitis $\mathrm{C}$, which effectively

\footnotetext{
${ }^{1}$ Department of Internal Medicine, Medical School, Sao Paulo State University (UNESP), Botucatu, SP, Brazil. ${ }^{2}$ Molecular Biology Laboratory, Blood Transfusion Center, HC-FMB, Sao Paulo State University (UNESP), Botucatu, SP, Brazil. ${ }^{3}$ Grupo Inmunovirologia, Facultad de Medicina, Universidad de Antioquia, UdeA, Medellín, Colombia. ${ }^{4}$ Department of Bioprocess and Biotechnology, College of Agricultural Sciences, Sao Paulo State University (UNESP), Botucatu, SP, Brazil. ${ }^{5}$ Med-Research Institute of Medicines, Faculdade de Farmácia da Universidade de Lisboa, Lisboa, Portugal. ${ }^{6}$ Instituto de Medicina Molecular João Lobo Antunes, Faculdade de Medicina, Universidade de

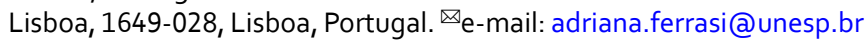


reduce the risks for hepatocellular carcinoma ${ }^{8,9}$, these resources are still not widely available to all patients, therefore, hepatocellular carcinoma still represents a public health problem.

HCV chronic infection promotes, in the long term, inflammation, chronic liver injury, fibrosis, dysplasia, and cirrhosis ${ }^{10}$. Hepatic fibrosis is characterized by excess accumulation of extracellular matrix resulting from the healing process of chronic lesions suffered by the liver cells, caused by various pathogenic factors. Over time, the accumulation of excess fibrous connective tissue distorts the normal parenchymal structure of the organ, forming septa and nodules that impair portal blood flow, leading to hypertension and cirrhosis. This tissue context is accompanied by the recruitment of immune cells whose cytokines and growth factors stimulate fibrogenesis. Thus, chronic stimulation of tissue regeneration and the pro-inflammatory environment could somehow, predispose to the development of hepatocellular carcinoma ${ }^{11,12}$. In Western countries, including Brazil, 70-80\% of HCC cases are associated with cirrhosis secondary to chronic B or $\mathrm{C}$ virus infection ${ }^{13,14}$. Genetic and epigenetic alterations are accumulated over decades of chronic injury and may affect the functioning of tumor suppressor genes and protooncogenes, essential for the control of proliferation, metabolism, adhesion and cell death ${ }^{15,16}$. The lncRNAs are transcribed larger than 200 base pairs, devoid of open read frame (ORF). They are transcribed by RNA polymerase II and are frequently processed and polyadenylated ${ }^{17}$. The expression of these molecules is tissue-specific and varies according to the physiological cell status ${ }^{18,19}$. The lncRNAs could regulate the expression of protein coding genes, both proximally (cis) and distally (trans) ${ }^{20}$, as well as acting at epigenetic ${ }^{21}$ and/or post-transcriptional levels ${ }^{22}$. Studies have demonstrated the role of various lncRNAs with oncogenic or tumor suppressor activities, suggesting a great potential in the treatment, diagnosis or indicator of prognosis in cancer $^{23-25}$. The development of cancer is a multi-step process involving genetic and cellular changes, and advances in molecular techniques, such as next generation sequencing, have shown that genetic alterations precede histological derangements ${ }^{26-29}$ and are accumulated step by step during the malignant transformation of normal cells into cancer cells. This knowledge reinforces the importance of the search for new lncRNAs involved in the carcinogenesis and progression of HCC. In this context, the aim of this study was to evaluate the global expression profile of non-coding long RNAs (lncRNA) in hepatic tissue samples with different stages of fibrosis associated with chronic hepatitis $\mathrm{C}$, hepatocellular carcinoma and normal liver, in order to identify new lncRNAs that could contribute to study the progression of hepatic fibrosis to hepatocellular carcinoma associated with chronic hepatitis $\mathrm{C}$ virus infection.

\section{Materials and methods}

Subject samples and ethics statement. Liver tissue specimens enrolled in the study, were collected in the Viral Hepatitis Outpatient Clinic of Botucatu Medical School, UNESP, Brazil. The case groups consisted of 15 patients with chronic hepatitis C, 3 patients with hepatocellular carcinoma (stage II; AJCC 8th TNM staging system) and the control group was composed for 3 specimens of normal liver. For the case group only were included detectable HCV-RNA cases, no previous hepatitis $\mathrm{C}$ treatment (naïve patients) or anti-cancer therapy and known fibrosis stage or clinical diagnosis of cirrhosis by image. The METAVIR ${ }^{30}$ grading was used, considering F0 (absent fibrosis), F1-F2 (moderate fibrosis) and F3-F4 (advanced fibrosis). Liver tissue specimens from patients with hepatitis C were collected by percutaneous biopsy and HCC samples were obtained immediately after surgical resection. This study was approved by the Ethics Committee on Research of Sao Paulo State University, conform to the provisions of the Declaration of Helsinki. All participants of the study signed individual informed consent forms.

Tissue sample preparation and RNA extraction. Liver tissue samples were stored in RNA later and stored at $-80^{\circ} \mathrm{C}$. A sample of $50 \mathrm{mg}$ tissue was triturated using Precellys 24-Dual homogenizer (Bertin Technologies, Rockville, Washington D.C., USA). The total RNA was extracted using TRIzol (Thermo Scientific, USA), according to the manufacturer's instructions. The RNA was quantitated by spectrophotometry using Qubit RNA Assay Kit in Qubit 2.0 Flurometer (Thermo Scientific, USA). RNA Integrity was ensured by obtaining RNA Integrity Number - RIN > 8 with Agilent 2100 Bioanalyzer (Agilent Technologies, Germany). RNA samples were treated with DNA Free Kit (Thermo Scientific, USA) to remove genomic DNA contamination.

Library preparation and Illumina sequencing. Each sample was diluted to the same concentration and each cDNA library was prepared from a pool of total RNAs from hepatic tissues with the following characteristics: a) Absent fibrosis (F0): RNA pooled of 3 specimens in F0 stage; b) Moderate fibrosis (F1, F2): RNA pooled of 3 specimens in F1 stage and 3 specimens in F2 stage; c) Advanced fibrosis (F3, F4): RNA pooled of 3 specimens in F3 stage and 3 specimens in F4 stage; d) Hepatocellular carcinoma: RNA pooled of 3 specimens of hepatocellular carcinoma; e) Normal liver: 3 non-tumor liver tissue samples and classified as normal after histopathological analysis. Libraries for Illumina sequencing were constructed from $1 \mu \mathrm{g}$ of total RNA with the TruSeq Stranded Total RNA Sample Preparation Kit v2 (Illumina). The constructed cDNA libraries were qualified by Agilent 2100 Bioanalyzer, quantified by qPCR with KAPA Library Quantification Kit (Kapa Biosystems, Inc.), and sequencing was performed on the NextSeq. 500 System (Illumina) platform using the NextSeq. 500/550 High Output v2 150 cycles (Illumina) sequencing kit.

Read Alignment and differential gene expression. The data output in fastq file format. Average Phred scores of $\geq 20$ per position were used for alignment. Paired-end reads for RNA were mapped to the human GRCh38 genome build using TopHat $2^{31}$, with this option-mate-inner-dist 200-mate-std-dev 100no-novel-juncs-min-intron-length 40 . Counts for RefSeq genes were obtained using HTSeq ${ }^{32}$ with the default settings and DESeq. 2 (version 1.4) ${ }^{33}$ was used to normalize expression counts. The changes in gene expression were considered statistically significant when $\mid$ fold change $\mid(F C) \geq 1.5$ and $p$-values $\leq 0.05$. For assess mRNA transcript abundance the reads were converted to reads per Thousand base pairs peak per million mapped reads (RPKM). 


\begin{tabular}{|c|c|c|c|c|c|}
\hline IncRNA & Name/Description & Class & $\begin{array}{l}\text { Cytogenetic } \\
\text { location }\end{array}$ & $\begin{array}{l}\text { Differential } \\
\text { expression }\end{array}$ & Phenotype \\
\hline LINC01748 & $\begin{array}{l}\text { Long intergenic non-protein coding } \\
\text { RNA } 1748\end{array}$ & antisense & $1 \mathrm{p} 32.1$ & up-regulated & unknown \\
\hline AL928742.1 & New transcript, Uncharacterized & intergenic & $14 \mathrm{q} 32.33$ & up-regulatedin & unknown \\
\hline MMP2-AS1 & MMP2 antisense RNA 1 & antisense & $16 \mathrm{q} 12.2$ & up-regulatedin & unknown \\
\hline HULC & Highly up-regulatedin liver cancer RNA & intergenic & $6 \mathrm{p} 24.3$ & down-regulated & $\begin{array}{l}\text { up-regulated in HCC and } \\
\text { others tumors }\end{array}$ \\
\hline LINC02197 & $\begin{array}{l}\text { Long intergenic non-protein coding } \\
\text { RNA } 2197\end{array}$ & intergenic & $5 q 13.2$ & down-regulated & unknown \\
\hline LINC02535 & $\begin{array}{l}\text { Long intergenic non-protein coding } \\
\text { RNA } 2535\end{array}$ & intergenic & $6 \mathrm{q} 14.3$ & down-regulated & unknown \\
\hline LINC00844 & $\begin{array}{l}\text { Long intergenic non-protein coding } \\
\text { RNA } 844\end{array}$ & intergenic & $10 \mathrm{q} 21.1$ & down-regulated & unknown \\
\hline AC008549.1 & New transcript, Uncharacterized & intergenic & chr.5 & down-regulated & unknown \\
\hline LINC01018 & $\begin{array}{l}\text { Long intergenic non-protein coding } \\
\text { RNA } 1018\end{array}$ & intergenic & $5 p 15.31$ & down-regulated & down-regulated in HCC \\
\hline LINC01093 & $\begin{array}{l}\text { Long intergenic non-protein coding } \\
\text { RNA } 1093\end{array}$ & intergenic & $4 \mathrm{q} 35.1$ & down-regulated & down-regulated in HCC \\
\hline LINC02532 & $\begin{array}{l}\text { Long intergenic non-protein coding } \\
\text { RNA 2532 }\end{array}$ & intergenic & $6 \mathrm{q} 21$ & down-regulated & unknown \\
\hline CTXND1 & $\begin{array}{l}\text { Long Intergenic Non-Protein Coding } \\
\text { RNA } 1314\end{array}$ & antisense & $15 \mathrm{q} 25.1$ & down-regulated & $\begin{array}{l}\text { down-regulated in gastric } \\
\text { cancer and hepatoblastoma }\end{array}$ \\
\hline AC025271.2 & New transcript, Uncharacterized & antisense & $15 \mathrm{q} 21.3$ & down-regulated & unknown \\
\hline LINC02037 & $\begin{array}{l}\text { Long intergenic non-protein coding } \\
\text { RNA } 2037\end{array}$ & intergenic & $3 \mathrm{q} 29$ & down-regulated & unknown \\
\hline AC016044.1 & New transcript, Uncharacterized & intergenic & $15 \mathrm{q} 21.3$ & down-regulated & unknown \\
\hline AC021242.2 & New transcript, Uncharacterized & intergenic & $8 \mathrm{p} 23.1$ & down-regulated & unknown \\
\hline AC010280.3 & New transcript, Uncharacterized & intergenic & $5 q 13.1$ & down-regulated & unknown \\
\hline LINC01817 & $\begin{array}{l}\text { Long intergenic non-protein coding } \\
\text { RNA } 1817\end{array}$ & intergenic & $2 \mathrm{q} 23.3$ & down-regulated & unknown \\
\hline LINC01818 & $\begin{array}{l}\text { Long intergenic non-protein coding } \\
\text { RNA } 1818\end{array}$ & intergenic & $2 \mathrm{q} 23.3$ & down-regulated & unknown \\
\hline AL035706.1 & New transcript, Uncharacterized & intergenic & $1 \mathrm{p} 31.1$ & down-regulated & unknown \\
\hline AL139161.1 & New transcript, Uncharacterized & intergenic & $1 \mathrm{q} 42.3$ & down-regulated & unknown \\
\hline LINC02027 & $\begin{array}{l}\text { Long intergenic non-protein coding } \\
\text { RNA } 2027\end{array}$ & intergenic & $3 \mathrm{p} 12.2$ & down-regulated & down-regulated in HCC \\
\hline LINC01780 & $\begin{array}{l}\text { Long intergenic non-protein coding } \\
\text { RNA } 1780\end{array}$ & intergenic & $1 \mathrm{p} 12$ & down-regulated & unknown \\
\hline LINC02499 & $\begin{array}{l}\text { Long intergenic non-protein coding } \\
\text { RNA } 2499\end{array}$ & intergenic & $4 \mathrm{q} 13.3$ & down-regulated & unknown \\
\hline AC105105.2 & New transcript, Uncharacterized & & $18 \mathrm{q} 21.31$ & down-regulated & unknown \\
\hline AC015845.2 & New transcript, Uncharacterized & intergenic & $17 \mathrm{q} 22$ & down-regulated & unknown \\
\hline LINC01370 & $\begin{array}{l}\text { Long intergenic non-protein coding } \\
\text { RNA } 1370\end{array}$ & intergenic & $20 \mathrm{q} 12$ & down-regulated & unknown \\
\hline AC087521.1 & New transcript, Uncharacterized & antisense & $11 \mathrm{p} 11.2$ & down-regulated & unknown \\
\hline AP001043.1 & New transcript, Uncharacterized & intergenic & $21 \mathrm{q} 22.2$ & down-regulated & unknown \\
\hline AP001043.2 & New transcript, Uncharacterized & intergenic & $21 \mathrm{q} 22.2$ & down-regulated & unknown \\
\hline LINC00313 & $\begin{array}{l}\text { Long Intergenic Non-Protein Coding } \\
\text { RNA } 313\end{array}$ & intergenic & $21 \mathrm{q} 22.3$ & down-regulated & $\begin{array}{l}\text { upregulated in lung and } \\
\text { papillary thyroid cancer }\end{array}$ \\
\hline AP001781.1 & New transcript, Uncharacterized & intergenic & $11 \mathrm{q} 23.1$ & down-regulated & unknown \\
\hline XIST & $\mathrm{X}$ inactive specific transcript & intergenic & $\mathrm{Xq} 13.2$ & down-regulated & $\begin{array}{l}\text { aberrantly expressed in } \\
\text { various cancers, including } \\
\text { HCC }\end{array}$ \\
\hline TSIX & TSIX Transcript, XIST Antisense RNA & intergenic & Xq13.2 & down-regulated & HCC \\
\hline LINC00261 & $\begin{array}{l}\text { Long Intergenic Non-Protein Coding } \\
\text { RNA } 261\end{array}$ & sense_intronic & $20 \mathrm{p} 11.21$ & down-regulated & $\begin{array}{l}\text { down-regulated in HCC } \\
\text { and others tumors }\end{array}$ \\
\hline AC115619.1 & New transcript, Uncharacterized & intergenic & $2 \mathrm{p} 24.1$ & down-regulated & unknown \\
\hline
\end{tabular}

Table 1. LncRNA differentially expressed ( $\mathrm{p} \leq 0.05$ and fold change $\geq 1.5$ ) from hepatic tissues with different stage of fibrosis in chronic hepatitis $\mathrm{C}$, hepatocellular carcinoma and normal tissue by Illumina-based RNA-seq.

Gene ontology (GO) enrichment analysis. GO enrichment was performed using the ClueGO Cytoscape plugin $^{34}$, using a hypergeometric test with a Benjamini and Hochberg False Discovery Rate correction. A p-value cut-off of 0.05 was used to identify enriched processes. 


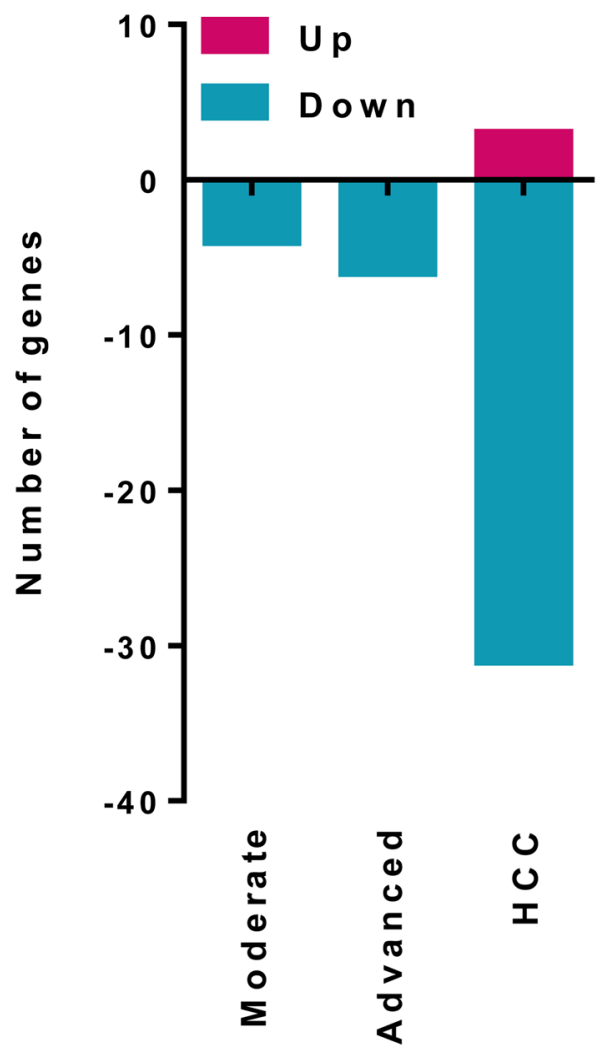

Figure 1. Bar plot representing the total number of up-regulated and down-regulated genes in moderate fibrosis, advanced fibrosis and hepatocellular carcinoma groups.

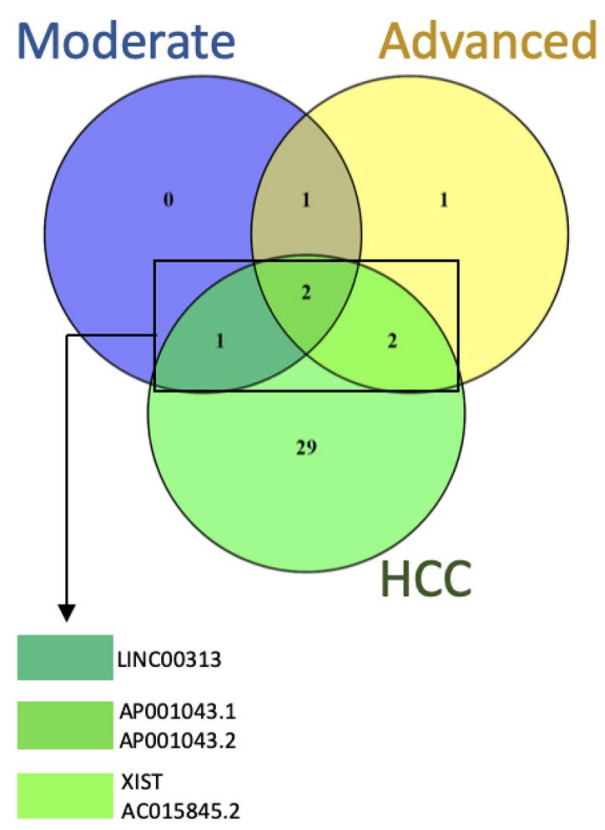

Figure 2. Venn diagram of the differentially expressed lncRNA: The number in each circle represents the amount of differentially expressed genes between the different comparisons: moderate and advanced fibrosis and hepatocellular carcinoma (HCC) groups. 


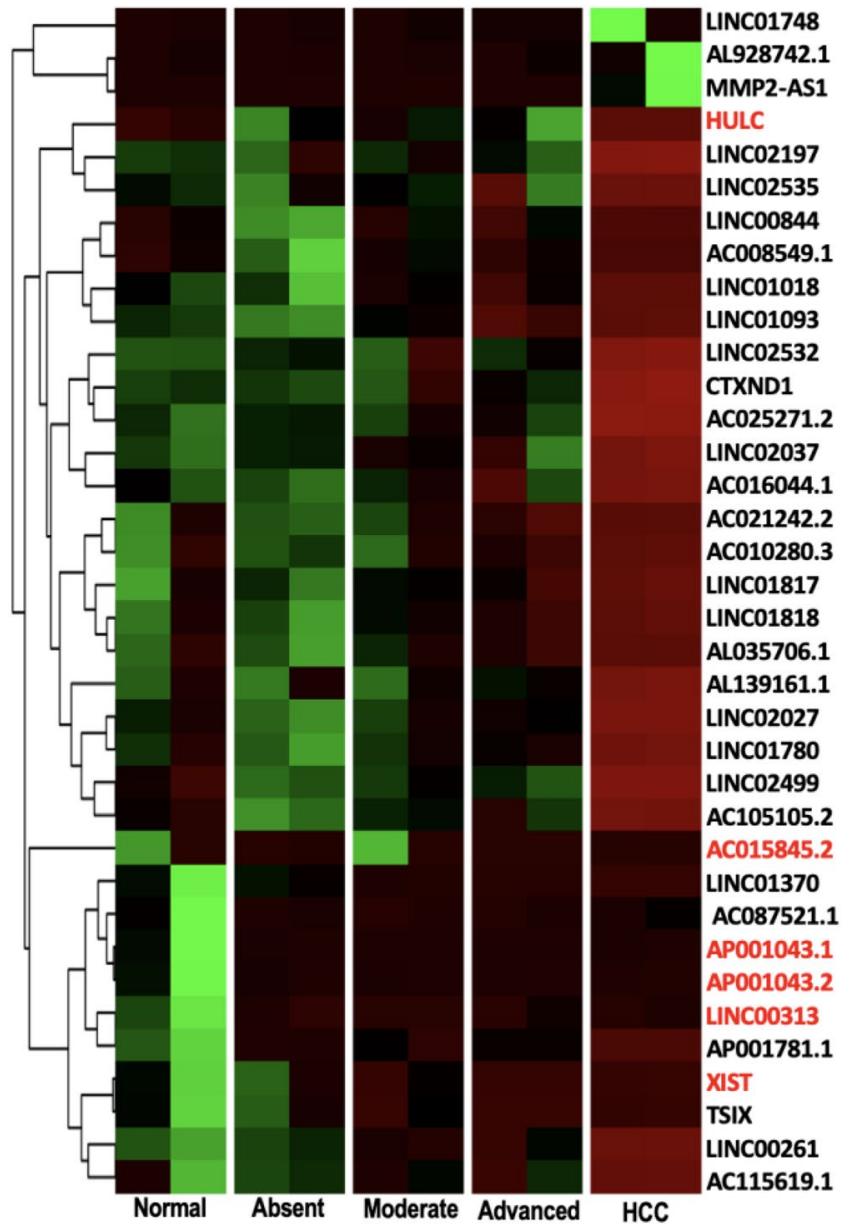

Figure 3. Heatmap of 36 Z-score normalized differentially expressed lncRNA of normal samples, absent fibrosis, moderate fibrosis, advanced fibrosis and hepatocellular carcinoma (HCC) by unsupervised hierarchical clustering analysis. Down-regulated and up-regulated lncRNA are shown in red and green, respectively.

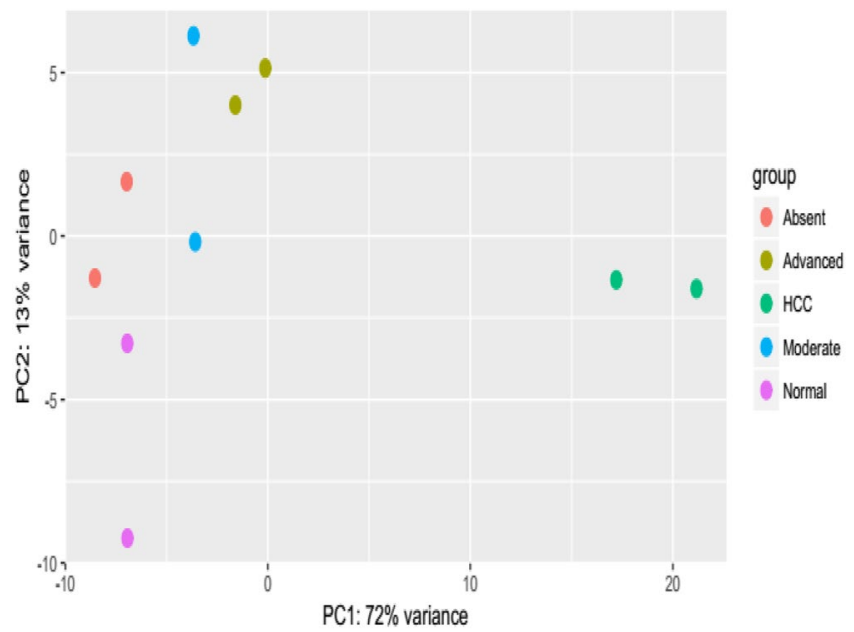

Figure 4. Principal component analysis (PCA) of the lncRNA expression data of normal samples, absent fibrosis, moderate fibrosis, advanced fibrosis and hepatocellular carcinoma (HCC). 


\section{Results and Discussion}

In this study, we obtained the differential expression profile of lncRNA from hepatic tissues with different stage of fibrosis in chronic hepatitis $\mathrm{C}$, hepatocellular carcinoma and normal tissue by Illumina-based RNA-seq. A total of 36 lncRNA were differentially expressed ( $p \leq 0.05$ and $\mid$ fold change $\mid \geq 1.5$ ). Table 1 shows the differentially expressed lncRNAs. When the pathological tissues (fibrosis and carcinoma) were compared to normal hepatic tissue, we identified 4, 6 and 34 differentially expressed lncRNAs in moderate fibrosis, advanced fibrosis and hepatocellular carcinoma groups, respectively (Fig. 1). No significant differential expression of lncRNAs was detected in the absent fibrosis group (F0).

Additionally, we found two lncRNAs (AP001043.1 and AP001043.2) differentially expressed (down-regulated) in common among the different groups studied (Fig. 2). Both are new intergenic transcripts, located in $21 \mathrm{q} 22.2$ locus and have never been found deregulated in other disorders.

AC015845.2 and XIST are down-regulated in both advanced fibrosis and hepatocellular carcinoma (Fig. 2). AC015845.2 is a new transcript, located in $17 \mathrm{q} 22$ locus and not yet characterized and has not yet been related to other diseases. XIST (X-inactive specific transcript) is known for its key role in dosage compensation by randomly inactivating one of the $\mathrm{X}$ chromosomes in mammalian females during embryonic development ${ }^{35}$. Recently, Yildirim et al. (2013) showed that Xist deletion in mice hematopoietic cells induced highly aggressive myeloproliferative neoplasm and myelodysplastic syndrome (mixed MPN/MDS) in vivo. Other studies have investigated the relationship between XIST and human cancer including gastric cancer ${ }^{36,37}$, cervical cancer ${ }^{38}$, osteosarcoma ${ }^{39}$, prostate cancer ${ }^{40}$, glioblastoma ${ }^{41}$, breast cancer ${ }^{42,43}$ and hepatocellular carcinoma ${ }^{44,45}$. It is noteworthy that XIST and AC015845.2 transcripts were found down regulated exclusively in cases of advanced fibrosis and hepatocellular carcinoma, suggesting association with advanced disease.

HCC group had the highest proportion of differentially expressed lncRNA ( 34 lncRNAs) and of these, 29 were exclusive in this type of tissue (Fig. 2). A heatmap of the differentially expressed lncRNA revealed different expression patterns along the progression of fibrosis to hepatocellular carcinoma (Fig. 3). Three lncRNAs were up-regulated in HCC, and 31 were down-regulated. A search for the function of lncRNAs in databases (GENCODE, lncRNAdb, LNCipedia, GeneCards, Ensembl and OMIM) was performed. Fifteen of them are new transcripts and have not yet been characterized. However, some transcripts have already been described as involved in some types of tumors (Table 1), including hepatocellular carcinoma, reinforcing its association with HCC.

HULC (Highly up-regulated in liver cancer) was originally identified as the most overexpressed long non-coding RNA in hepatocellular carcinoma ${ }^{46}$. It plays a key role in tumorigenesis, such as promotion of cell survival, proliferation, invasion and angiogenesis ${ }^{47,48}$. Currently, up-regulation of HULC has been demonstrated in other cancer types, including gastric cancer, pancreatic cancer, osteosarcoma and hepatic metastasis of colorectal cancer, as reviewed by Yu et al. (2016) ${ }^{49}$. Interestingly, our results presented here indicate HULC down-regulated in HCC samples (Fig. 3). Although the mechanisms underlying HULC overexpression in many cancer types remain uncertain, studies have suggested a link between HULC overexpression and HBV infection ${ }^{50}$ by HBV X protein $(\mathrm{HBx})$, an oncogenic viral protein involved in HBV pathogenicity, both in HCC and in non-tumor tissues of the liver ${ }^{51}$. HULC levels increases according to tumor grade and aggressiveness, indicating its utility as a prognostic indicator ${ }^{52}$. HULC studies on HCV-related carcinoma are scarce, so the non-agreement of our data with studies published in HBV-related HCC could suggest that HULC dysregulation occurs by a different pathway in HCV-related HCC, stimulating further investigations. In addition, the tumors analyzed here were classified as grade I of Edmondson and Steiner, which report the lower levels of HULC expression.

LINC01018, also called SRHC, was down-regulated in HCC, corroborating the findings of Zheng et al..$^{53}$ that found lower levels of expression in HCC samples with a high serum a-fetoprotein level and a low degree of differentiated tumors. In addition, up-regulation of LINC01018 was shown to decrease proliferation while promoting apoptosis of HCC cells ${ }^{54}$. LINC02027 (alias LOC728290) was found down-regulated in HCC, as also observed by Zhang et al. ${ }^{55}$. Down-regulation was positively associated with increased serum $\alpha$-fetoprotein levels and microvascular invasion. Determination of serum $\alpha$-fetoprotein levels is essential in the clinical diagnosis of liver cancer, suggesting that LINC02027 may be a promising biomarker for HCC. Our data show that lower levels of LINC01018 and LINC02027 can already be observed since advanced fibrosis, showing potential as early markers of HCC.

LINC00261 was down-regulated in moderate fibrosis, advanced fibrosis and hepatocellular carcinoma groups. Recent studies indicate that LINC00261 acts as a tumor suppressor involved in several tumors, such as gastric cancer, lung cancer, choriocarcinoma and $\mathrm{HCC}^{56}$. Upregulation LINC00261 significantly inhibited Notch signaling pathway, aberrantly activated in tumors and plays the tumor-promoting role in $\mathrm{HCC}^{56}$.

LINC01093 shows significant downregulation in HCC tissues in our study and, recently, He et al. ${ }^{57}$ correlated with HCC TNM stage and as a prognostic predictor for HCC patients. Overexpression significantly suppresses HCC cell proliferation and metastasis in vitro and in vivo. Conversely, its knockdown promotes HCC progression.

Other down-regulated lncRNAs found in our study (CTXND1 and LINC00313) were also associated with other tumors, such as hepatoblastoma, lung, gastric and papillary thyroid cancers (Table 1).

It is noteworthy that three lncRNAs (LINC01748, AL928742.1 and MMp2-AS1) found overexpressed were observed exclusively in the HCC. Both are novel transcripts and studies should be conducted to clarify their cellular function and their role as tumor marker.

The inspection of the lncRNAs through principal component analysis (PCA), revealed a distinct separation of the hepatocellular carcinoma from the other groups (Fig. 4). Moreover, the PCA uncovered a heterogeneity on transcriptome regulation in non-tumor groups, evidenced by the spatial dispersion of the samples in the PCA. This heterogeneity in transcriptome is expected since the progression of the hepatic lesion is a stochastic process and each patient develop variable hepatic condition until the carcinogenesis. 
Although there are already studies on lncRNA in hepatocellular carcinoma, this is the first study conducted in samples exclusively of HCV-related liver and HCV HCC.

These findings are limited to the population studied due to the small sample size, however, the observed data are interesting and should encourage further studies with samples from different populations.

The results of the present study showed the deregulation of some lncRNA already classified as tumor suppressors in HCC and other cancers, as well as some unpublished lncRNA whose function is unknown. Some of these lncRNAs are dysregulated since the early stages of liver injury in patients with hepatitis C, others overexpressed only in tumor tissue, indicating potential clinical applications in prognosis as well as a therapeutic target.

Received: 14 February 2020; Accepted: 28 May 2020;

Published online: 18 June 2020

\section{References}

1. Bray, F. et al. Global cancer statistics 2018: GLOBOCAN estimates of incidence and mortality worldwide for 36 cancers in 185 countries. CA Cancer J Clin. 68(6), 394-424, https://doi.org/10.3322/caac.21492 (2018).

2. Waly Raphael, S., Yangde, Z. \& Yuxiang, C. Hepatocellular carcinoma: focus on different aspects of management. ISRN Oncol. 2012, 421673, https://doi.org/10.5402/2012/421673 (2012).

3. Ministério da Saúde (Brasil). Secretaria de Atenção à Saúde. Portaria n 602 , de 26 de junho de 2012. Aprova as Diretrizes Diagnósticas e Terapêuticas do Câncer de Fígado no adulto. 2012:1-19.

4. Bruix, J. \& Reig, M. Sherman M. Evidence-Based Diagnosis, Staging, and Treatment of Patients with Hepatocellular Carcinoma. Gastroenterology. 150, 835-53, https://doi.org/10.1053/j.gastro.2015.12.041 (2016).

5. Marrero, J. A. et al. Diagnosis, staging and management of hepatocellular carcinoma: 2018 practice guidance by the American Association for the Study of Liver Diseases. Hepatology., https://doi.org/10.1002/hep.29913 (2018).

6. El-Serag, H. B. Epidemiology of viral hepatitis and hepatocellular carcinoma. Gastroenterology. 142(6), 1264-1273.e1, https://doi. org/10.1053/j.gastro.2011.12.061 (2012).

7. de Martel, C., Maucort-Boulch, D., Plummer, M. \& Franceschi, S. World-wide relative contribution of hepatitis B and C viruses in hepatocellular carcinoma. Hepatology. 62(4), 1190-200 (2015).

8. Terrault, N. A. et al. HCV TARGET Study Group. Effectiveness of Ledipasvir-Sofosbuvir Combination in Patients With Hepatitis C Virus Infection and Factors Associated With Sustained Virologic Response. Gastroenterology. 151(6), 1131-1140.e5, https://doi. org/10.1053/j.gastro.2016.08.004 (2016).

9. Razavi, H. et al. The present and future disease burden of hepatitis C virus (HCV) infection with today's treatment paradigm. $J$ Viral Hepat. 21(Suppl 1), 34-59, https://doi.org/10.1111/jvh.12248 (2014).

10. Baranova, A., Lal, P., Birerdinc, A. \& Younossi, Z. M. Noninvasive markers for hepatic fibrosis. BMC Gastroenterol. 11, 91, https:// doi.org/10.1186/1471-230X-11-91 (2011).

11. Ghany, M. G. et al. Progression of fibrosis in chronic hepatitis C. Gastroenterol. 124, 97-104 (2003).

12. Kamegaya, Y. et al. Hepatitis $\mathrm{C}$ virus acts as a tumor accelerator by blocking apoptosis in a mouse model of hepatocarcinogenesis. Hepatology. 41(3), 660-7 (2005).

13. Okuda, H. Hepatocellular carcinoma development in cirrhosis. Best Practice and Research. Clin Gastroenterol. 21, 1613 (2007).

14. Carrilho FJ, Kikuchi L, Branco F, Goncalves CS, Mattos AA; Brazilian HCC Study Group. Clinical and epidemiological aspects of hepatocellular carcinoma in Brazil. Clinics (Sao Paulo). 65(12):1285-90 (2010).

15. Liu, M., Jiang, L. \& Guan, X. Y. The genetic and epigenetic alterations in human hepatocellular carcinoma: a recent update. Protein Cell. 5(9), 673-91, https://doi.org/10.1007/s13238-014-0065-9 (2014).

16. Pogribny, I. P. \& Rusyn, I. Role of epigenetic aberrations in the development and progression of human hepatocellular carcinoma. Cancer Lett. 342(2), 223-30, https://doi.org/10.1016/j.canlet.2012.01.038 (2014).

17. Fatica, A. \& Bozzoni, I. Long non-coding RNAs: new players in cell differentiation and development. Nat Rev Genet. 15(1), 7-21, https://doi.org/10.1038/nrg3606 (2014).

18. Ward, M., McEwan, C., Mills, J. D. \& Janitz, M. Conservation and tissue-specific transcription patterns of long noncoding RNAs. J Hum Transcr. 1(1), 2-9 (2015).

19. Guttman, M. \& Rinn, J. L. Modular regulatory principles of large non-coding RNAs. Nature. 482(7385), 339-46, https://doi. org/10.1038/nature10887 (2012).

20. Spizzo, R., Almeida, M. I., Colombatti, A. \& Calin, G. A. Long non-coding RNAs and cancer: a new frontier of translational research? Oncogene. 31(43), 4577-87, https://doi.org/10.1038/onc.2011.621 (2012).

21. Sati, S., Ghosh, S., Jain, V., Scaria, V. \& Sengupta, S. Genome-wide analysis reveals distinct patterns of epigenetic features in long non-coding RNA loci. Nucleic Acids Res. 40(20), 10018-31, https://doi.org/10.1093/nar/gks776 (2012).

22. Yoon, J. H., Abdelmohsen, K. \& Gorospe, M. Posttranscriptional gene regulation by long noncoding RNA. J Mol Biol. 425(19), 3723-30, https://doi.org/10.1016/j.jmb.2012.11.024 (2013).

23. Liu, Q. et al. LncRNA loc285194 is a p53-regulated tumor suppressor. Nucleic Acids Res. 41(9), 4976-87, https://doi.org/10.1093/nar/ gkt182 (2013).

24. Spizzo, R., Almeida, M. I., Colombatti, A. \& Calin, G. A. Long non-coding RNAs and cancer: a new frontier of translational research? Oncogene. 31(43), 4577-87, https://doi.org/10.1038/onc.2011.621 (2012).

25. Wang, P. et al. Identification of lncRNA-associated competing triplets reveals global patterns and prognostic markers for cancer. Nucleic Acids Res. 43(7), 3478-89, https://doi.org/10.1093/nar/gkv233 (2015).

26. Lin, S. H. et al. The somatic mutation landscape of premalignant colorectal adenoma. Gut. 67(7), 1299-1305, https://doi. org/10.1136/gutjnl-2016-313573 (2018).

27. Huang, K. K. et al. Tan P. Genomic and Epigenomic Profiling of High-Risk Intestinal Metaplasia Reveals Molecular Determinants of Progression to Gastric Cancer. Cancer Cell. 33(1), 137-150.e5, https://doi.org/10.1016/j.ccell.2017.11.018 (2018).

28. Weaver, J. M. J. et al. OCCAMS consortium. Ordering of mutations in preinvasive disease stages of esophageal carcinogenesis. Nat Genet. 46(8), 837-843, https://doi.org/10.1038/ng.3013 (2014).

29. Yokoyama, A. et al. Age-related remodelling of oesophageal epithelia by mutated cancer drivers. Nature. 565(7739), 312-317, https://doi.org/10.1038/s41586-018-0811-x (2019).

30. Bedossa, P. \& Poynard, T. An algorithm for the grading of activity in chronic hepatitis C. The METAVIR Cooperative Study Group. Hepatology. 24, 289-293 (1996).

31. Kim, D. et al. TopHat2: accurate alignment of transcriptomes in the presence of insertions, deletions and gene fusions. Genome Biol. 14(4), R36, https://doi.org/10.1186/gb-2013-14-4-r36 (2013)

32. Anders, S., Pyl, P. T. \& Huber, W. HTSeq-a Python framework to work with high-throughput sequencing data. Bioinformatics. 31(2), 166-9, https://doi.org/10.1093/bioinformatics/btu638 (2015).

33. Love, M. I., Huber, W. \& Anders, S. Moderated estimation of fold change and dispersion for RNA-seq data with DESeq. 2. Genome Biol. 15(12), 550 (2014). 
34. Bindea G et al. ClueGO: a Cytoscape plug-in to decipher functionally grouped gene ontology and pathway annotation networks. Bioinformatics. Apr 15;25(8):1091-3, https://doi.org/10.1093/bioinformatics/btp101 (2009).

35. Sahakyan, A., Yang, Y. \& Plath, K. The Role of Xist in X-Chromosome Dosage Compensation. Trends Cell Biol. 28(12), 999-1013, https://doi.org/10.1016/j.tcb.2018.05.005 (2018).

36. Chen, D. L. et al. Long non-coding RNA XIST regulates gastric cancer progression by acting as a molecular sponge of miR-101 to modulate EZH2 expression. J Exp Clin Cancer Res. 35(1), 142, https://doi.org/10.1186/s13046-016-0420-1 (2016).

37. Ma, L. et al. Long non-coding RNA XIST promotes cell growth and invasion through regulating miR-497/MACC1 axis in gastric cancer. Oncotarget. 8(3), 4125-4135, https://doi.org/10.18632/oncotarget.13670 (2017).

38. Kobayashi, R. et al. Increased expression of long non-coding RNA XIST predicts favorable prognosis of cervical squamous cell carcinoma subsequent to definitive chemoradiation therapy. Oncol Lett. 12(5), 3066-3074 (2016).

39. Zhang, R. \& Xia, T. Long non-coding RNA XIST regulates PDCD4 expression by interacting with miR-21-5p and inhibits osteosarcoma cell growth and metastasis. Int J Oncol. 51(5), 1460-1470, https://doi.org/10.3892/ijo.2017.4127 (2017).

40. Du, Y. et al. LncRNA XIST acts as a tumor suppressor in prostate cancer through sponging miR-23a to modulate RKIP expression. Oncotarget. 8(55), 94358-94370, https://doi.org/10.18632/oncotarget.21719 (2017).

41. Cheng, Z. et al. XIST Promotes Glioma Tumorigenicity and Angiogenesis by Acting as a Molecular Sponge of miR-429. J Cancer. 8(19), 4106-4116, https://doi.org/10.7150/jca.21024 (2017). 6.

42. Huang, Y. S., Chang, C. C., Lee, S. S., Jou, Y. S. \& Shih, H. M. Xist reduction in breast câncer upregulates AKT phosphorylation via HDAC3-mediated repression of PHLPP1 expression. Oncotarget. 12;7(28), 43256-43266, https://doi.org/10.18632/oncotarget.9673 (2016).

43. Zheng, R. et al. Long non-coding RNA XIST inhibited breast cancer cell growth, migration, and invasion via miR-155/CDX1 axis. Biochem Biophys Res Commun. 15;498(4), 1002-1008, https://doi.org/10.1016/j.bbrc.2018.03.104 (2018).

44. Chang, S., Chen, B., Wang, X., Wu, K. \& Sun, Y. Long non-coding RNA XIST regulates PTEN expression by sponging miR-181a and promotes hepatocellular carcinoma progression. BMC Cancer. 17(1), 248, https://doi.org/10.1186/s12885-017-3216-6 (2017).

45. Kong, Q. et al. LncRNA XIST functions as a molecular sponge of miR-194-5p to regulate MAPK1 expression in hepatocellular carcinoma cell. J Cell Biochem. 119(6), 4458-4468, https://doi.org/10.1002/jcb.26540 (2018).

46. Panzitt, K. et al. Characterization of HULC, a novel gene with striking up-regulation in hepatocellular carcinoma, as noncoding RNA. Gastroenterology. 132(1), 330-42 (2007).

47. Zhao, Y. et al. Role of long non-coding RNA HULC in cell proliferation, apoptosis and tumor metastasis of gastric cancer: a clinical and in vitro investigation. Oncol Rep. 31(1), 358-64, https://doi.org/10.3892/or.2013.2850 (2014).

48. Lu, Z. et al. Long non-coding RNA HULC promotes tumor angiogenesis in liver cancer by up-regulating sphingosine kinase 1 (SPHK1). Oncotarget. 7(1), 241-54, https://doi.org/10.18632/oncotarget.6280 (2016).

49. Yu, X., Zheng, H., Chan, M. T. \& Wu, W. K. HULC: an oncogenic long non-coding RNA in human cancer. J Cell Mol Med. 21(2), 410-417, https://doi.org/10.1111/jcmm.12956 (2017).

50. Matouk, I. J. et al. Highly upregulated in liver cancer noncoding RNA is overexpressed in hepatic colorectal metastasis. Eur J Gastroenterol Hepatol. 21(6), 688-92 (2009).

51. Du, Y. et al. Elevation of highly up-regulated in liver cancer (HULC) by hepatitis B virus X protein promotes hepatoma cell proliferation via down-regulating p18. J Biol Chem. 287(31), 26302-11, https://doi.org/10.1074/jbc.M112.342113 (2012).

52. Xie, H., Ma, H. \& Zhou, D. Plasma HULC as a promising novel biomarker for the detection of hepatocellular carcinoma. Biomed Res Int. 2013, 136106, https://doi.org/10.1155/2013/136106 (2013).

53. Zheng, H. et al. Epigenetically silenced long noncoding-SRHC promotes proliferation of hepatocellular carcinoma. J Cancer Res Clin Oncol. 141(7), 1195-203, https://doi.org/10.1007/s00432-014-1871-4 (2015).

54. Wang $\mathrm{S}$ et al. LINC01018 confers a novel tumor-suppressor role in hepatocellular carcinoma through sponging microRNA-182-5p. Am J Physiol Gastrointest Liver Physiol, https://doi.org/10.1152/ajpgi.00005.2019 [Epub ahead of print] (2019).

55. Zhang, S. G. et al. Decreased expression of long non-coding RNA LOC728290 in human hepatocellular carcinoma. Oncol Lett. Oct;14(4):4551-4556, https://doi.org/10.3892/ol.2017.6776 (2017).

56. Zhang, H. F., Li, W. \& Han, Y. D. LINC00261 suppresses cell proliferation, invasion and Notch signaling pathway in hepatocellular carcinoma. Cancer Biomark. 21(3), 575-582, https://doi.org/10.3233/CBM-170471 (2018).

57. He, J. et al. A novel, liver-specific long noncoding RNA LINC01093 suppresses HCC progression by interaction with IGF2BP1 to facilitate decay of GLI1 mRNA. Cancer Lett. 450, 98-109, https://doi.org/10.1016/j.canlet.2019.02 (2019).

\section{Acknowledgements}

This work was supported by the grant from São Paulo Research Foundation - FAPESP (grant number 2013/21214-9).

\section{Author contributions}

A.F.: conception and design of the study, experimental work and acquisition, analysis and interpretation of data, manuscript writing, and final approval of the manuscript. G.F.: conception and design of the study, analysis and interpretation of data, revising draft critically, and final approval of the manuscript. R.G.: conception and design of the study, analysis and interpretation of data, revising draft critically, and final approval of the manuscript. G.S.: conception and design of the study, analysis and interpretation of data, revising draft critically, and final approval of the manuscript. J.G.: conception and design of the study, analysis and interpretation of data, revising draft critically, and final approval of the manuscript. M.C.: analysis and interpretation of data, revising draft critically, and final approval of the manuscript. F.E.: conception and design of the study, analysis and interpretation of data, revising draft critically, and final approval of the manuscript. M.P.: conception and design of the study, analysis and interpretation of data, manuscript writing, and final approval of the manuscript.

\section{Competing interests}

The authors declare no competing interests.

\section{Additional information}

Correspondence and requests for materials should be addressed to A.C.F.

Reprints and permissions information is available at www.nature.com/reprints.

Publisher's note Springer Nature remains neutral with regard to jurisdictional claims in published maps and institutional affiliations. 
(c) (i) Open Access This article is licensed under a Creative Commons Attribution 4.0 International License, which permits use, sharing, adaptation, distribution and reproduction in any medium or format, as long as you give appropriate credit to the original author(s) and the source, provide a link to the Creative Commons license, and indicate if changes were made. The images or other third party material in this article are included in the article's Creative Commons license, unless indicated otherwise in a credit line to the material. If material is not included in the article's Creative Commons license and your intended use is not permitted by statutory regulation or exceeds the permitted use, you will need to obtain permission directly from the copyright holder. To view a copy of this license, visit http://creativecommons.org/licenses/by/4.0/.

(C) The Author(s) 2020 